\title{
CAFE regulations and the overview of the passenger car market within the European Union
}

DOI: https://doi.org/10.7307/ptsm.2020.8

\author{
Luka Međurečan ${ }^{1}$, Matija Sikirić ${ }^{2}$ \\ Gašparić Grupa ${ }^{1}$, Faculty of Transport and Traffic Sciences ${ }^{2}$
}

\section{Keywords: \\ CAFÉ regulation \\ Passenger vehicle \\ Vehicle emission \\ Vehicle market \\ European Union}

\begin{abstract}
Vehicles with internal combustion engines (ICE) currently represent the most prevalent form of road transport. Although level of emission per vehicle have drastically decreased, their emissions have significant impacts on the environment and health. The emergence of vehicles powered by more environmentally friendly systems has resulted in a change in perceptions, as they result in a reduction in pollution and other negative impacts of the transport system. It is for this reason that the goal has been set, to reduce the market for vehicles with only internal combustion and focus on encouraging the purchase of more sustainable options. The aim of this paper is to review the regulations in the field of passenger car markets in the European Union, and to establish historical trends, as well as to identify goals for future market development.
\end{abstract}

\section{Introduction}

Vehicles with internal combustion engines (ICE) currently represent the most prevalent form of road transport. Although level of emission per vehicle have drastically decreased, their emissions have significant impacts on the environment and health.

The transport sector represents more than a quarter of Europe's greenhouse gas emissions, with over 70\% of transport emissions coming from road transport. [1] Internal combustion engine (ICE) vehicles are also key sources of air pollution, such as particulate matter (PM) and nitrogen oxides (NOx). [2]

In Europe, authorities in the United Kingdom, France, Germany, Ireland, the Netherlands and Norway have declared their intention to implement bans on the sale or registration of new ICE vehicles with starting dates ranging from 2030 to 2040 . Moreover, many countries have already adopted purchase or tax incentive programs for electric vehicles (EV): 24 Member States currently offer some form of tax incentive, while 12 offer bonus payments or premiums to buyers.

\section{CAFÉ regulative}

CAFE regulative stands for Clean Air for Europe programme (CAFE). The CAFE programme was established to support the European Commission's development of the Thematic Strategy on air pollution, the Directive on Ambient Air Quality and Cleaner Air for Europe and its Impact Assessment. [3]

In total passenger ICE vehicles are responsible for around 12\% of total EU emissions of carbon dioxide (CO2), the main greenhouse gas. Regulation (EC) 443/2009, set mandatory emission reduction targets for new cars. The first target fully applied from 2015 onward and a new target will be phased in in 2020 and fully apply from 2021 onward. On 17 April 2019, the European Parliament and the Council adopted Regulation (EU) 2019/631 which introduces CO2 emission performance standards for new passenger cars and new vans for 2025 and 2030. The new Regulation started applying on 1 January 2020 and has replaced and repealed Regulation (EC) 443/2009. [3] 


\section{Target 2015}

Following a phase in from 2012 onward, a target of 130 grams of CO2 per kilometre applied for the EU fleetwide average emission of new passenger cars between 2015 and 2019. Emissions of $130 \mathrm{~g} \mathrm{CO} 2 / \mathrm{km}$ correspond to a fuel consumption of around 5.6 litres per $100 \mathrm{~km}(1 / 100 \mathrm{~km})$ of petrol or $4.9 \mathrm{l} / 100 \mathrm{~km}$ of diesel. This EU fleet-wide target was already reached in 2013, two years ahead of schedule. The average emissions of new cars registered in 2019 in the EU28, Iceland and Norway were $122.4 \mathrm{~g} \mathrm{CO} / \mathrm{km}$ (provisional EEA data). [4]

\section{Target 2020-21}

From 2021, phased in from 2020, the EU fleet-wide average emission target for new cars will be $95 \mathrm{~g} \mathrm{CO} 2 / \mathrm{km}$. This emission level corresponds to a fuel consumption of around 4.1 1/100 km of petrol or 3.6 1/100 km of diesel. [4]

\section{Specific emission targets for manufacturers}

The binding emission targets for manufacturers are set according to the average mass of their vehicles, using a limit value curve. This means that manufacturers of heavier cars are allowed higher emissions than manufacturers of lighter cars. The curve is set in such a way that the targets for the EU fleet-wide average emissions are achieved. [3]

In 2020, the emission targets will apply for each manufacturer's 95\% least emitting new cars. From 2021 onward, the average emissions of all newly registered cars of a manufacturer will have to be below the target. [4]

\section{Phase-in of requirements}

The target of $130 \mathrm{~g} / \mathrm{km}$ was phased in between 2012 and 2015. A phase-in period will also apply to the target of $95 \mathrm{~g} / \mathrm{km}$. In 2020, the emission targets will apply for each manufacturer's $95 \%$ least emitting new cars. From 2021 on, the average emissions of all newly registered cars of a manufacturer will have to be below the target. [4]

\section{Penalty payments for excess emissions}

If the average $\mathrm{CO} 2$ emissions of a manufacturer's fleet exceed its target in a given year, the manufacturer has to pay an excess emissions premium for each car registered. Since 2019 , the penalty is $€ 95$ for each $\mathrm{g} / \mathrm{km}$ of target exceedance. [4]

\section{Eco-innovations}

To encourage eco-innovation, manufacturers can be granted emission credits for vehicles equipped with innovative technologies for which it is not possible to demonstrate the CO2-reducing effects during the test procedure used for vehicle type approval. Such emission savings must be demonstrated based on independently verified data. The maximum emission credits for these eco-innovations per manufacturer are 7 $\mathrm{g} / \mathrm{km}$ per year. [5]

The eco-innovations mechanism rewards innovative technologies that produce real-world $\mathrm{CO} 2$ savings beyond what is measured over the standardized test cycle during vehicle type approval. Because $\mathrm{CO} 2$ savings from eco-innovation technologies count toward manufacturers' $\mathrm{CO} 2$ targets, manufacturers have an incentive to develop and deploy cost-effective eco-innovations to meet $\mathrm{CO} 2$ standards. In theory, providing credits to manufacturers for technologies that reduce real-world emissions can both reduce the cost of complying with the $\mathrm{CO} 2$ standards and increase total real-world reductions. However, if estimated eco-innovations $\mathrm{CO} 2$ savings exceed the amount of real-world reductions, or if credits are given that double-count $\mathrm{CO} 2$ reductions 
on the type-approval test, they can become a loophole and erode the benefits of the $\mathrm{CO} 2$ standards. Thus, it is critical to properly account for the real-world benefits of eco-innovations. [5]

Table 1. List of approved eco-innovations

\begin{tabular}{|c|c|c|c|}
\hline Company & Eco-innovation & Company & Eco-innovation \\
\hline Audi & LED lights & DENSO & Efficient alternator \\
\hline Valeo & Efficient alternator & Toyota & LED lights \\
\hline Daimler & $\begin{array}{l}\text { Engine compartment } \\
\text { encapsulation system }\end{array}$ & $\begin{array}{l}\text { Mitsubishi Electric } \\
\text { Corporation }\end{array}$ & Efficient alternator \\
\hline Bosch & $\begin{array}{l}\text { Adaptive state of charge } \\
\text { control in hybrids }\end{array}$ & Bosch & Efficient alternator \\
\hline $\begin{array}{l}\text { Automotive } \\
\text { Lighting } \\
\text { Reutlingen }\end{array}$ & LED lights & Valeo & Efficient alternator \\
\hline DENSO & Efficient alternator & MAHLE Behr & Enthalpy storage tank \\
\hline $\begin{array}{l}\text { Webasto Roof \& } \\
\text { Components }\end{array}$ & Solar roof & Honda & LED lights \\
\hline Bosch & Efficient alternator & Mazda & LED lights \\
\hline Bosch & Efficient alternator & Toyota & LED lights \\
\hline Daimler & LED lights & a2solar & Solar roof \\
\hline $\begin{array}{l}\text { Asola } \\
\text { Technologies }\end{array}$ & Solar roof & Valeo & Efficient alternator \\
\hline $\begin{array}{l}\text { Mitsubishi Electric } \\
\text { Corporation }\end{array}$ & Efficient alternator & BMW & Coasting function \\
\hline Porsche & Coasting function & & \\
\hline
\end{tabular}

Source: [5]

\section{Super credits}

Manufacturers are given additional incentives to put on the market zero- and low-emission cars emitting less than $50 \mathrm{~g} / \mathrm{km}$ through a "super-credits" system. This already applied between 2012 and 2015 and will apply again for the period 2020-2022. [4]

For the purpose of calculating a manufacturer's average specific emissions, such cars will then be counted as [4]:

$>2$ vehicles in 2020 ;

$>1.67$ vehicles in 2021 ;

1.33 vehicles in 2022 .

A cap on the super-credits is set at $7.5 \mathrm{~g} / \mathrm{km}$ per manufacturer over the three years. [4]

\section{Manufacturer Pools}

Manufacturers can group together and act jointly to meet their emissions target. In forming such a pool, manufacturers must respect the rules of competition law. Passenger cars and vans ('light commercial vehicles') are responsible for around $12 \%$ and $2.5 \%$, respectively, of total EU emissions of carbon dioxide (CO2), the main greenhouse gas. [6] 


\section{Benefits}

The new Regulation will [6]:

contribute to the achievement of the EU's commitments under the Paris Agreement;

$>$ reduce fuel consumption costs for consumers;

$>$ strengthen the competitiveness of EU automotive industry and stimulate employment.

Expected benefits include [6]:

$>$ a $23 \%$ reduction of greenhouse gas emissions from road transport in 2030 compared to 2005. This will support Member States in meeting their national targets under the Effort Sharing Regulation;

$>$ savings for consumers of around $€ 1,100$ over the lifetime of an average new car bought in 2030 and nearly $€ 4,000$ for an average new van;

$>$ positive impacts on employment across the overall economy, with around 60,000 jobs created by 2030 and up to 80,000 if batteries are produced in the EU;

$>$ a smooth and gradual transition towards zero-emission mobility allowing for sufficient time to provide for an adequate reskilling and reallocation of workers in the automotive sector;

$>$ a signal for investors in refuelling and recharging infrastructure, which will ensure that the enabling conditions for deploying zero- and low-emission vehicles are fulfilled.

\section{Target levels}

Regulation (EU) 2019/631 sets new EU fleet-wide CO2 emission targets are set for the years 2025 and 2030, both for newly registered passenger cars and for newly registered vans. These targets are defined as a percentage reduction from the 2021 starting points [6]:

$>$ Cars: $15 \%$ reduction from 2025 on and $37.5 \%$ reduction from 2030 on;

$>$ Vans: $15 \%$ reduction from 2025 on and $31 \%$ reduction from 2030 on;

The specific emission targets for manufacturers to comply with, are based on the EU fleet-wide targets, considering the average test mass of a manufacturer's newly registered vehicles. [6]

\section{In-service verification}

Manufacturers are required to ensure correspondence between the $\mathrm{CO} 2$ emissions recorded in the certificates of conformity of their vehicles and the $\mathrm{CO} 2$ emissions of vehicles in-service measured according to the Worldwide Harmonised Light Vehicle Test Procedure (WLTP). This correspondence shall be verified by typeapproval authorities in selected vehicles. The authorities shall also verify the presence of any strategies artificially improving the vehicle's performance in the type-approval tests. [6]

Based on their findings, type-approval authorities shall, where needed, ensure the correction of the certificates of conformity and may take other necessary measures set out in the Type Approval Framework Regulation. Deviations found in the $\mathrm{CO} 2$ emissions of vehicles in service shall be reported to the Commission, who shall take them into account for the purpose of calculating the average specific emissions of a manufacturer. [6]

\section{Real-world emissions}

To prevent the gap between emissions tested in the laboratory and real-world emissions from increasing, the Commission shall, from 2021 on, regularly collect data on the real-world CO2 emissions and energy consumption of cars and vans using the on-board fuel consumption monitoring devices (OBFCM).

The Commission shall monitor how that gap evolves between 2021 and 2026 and, on that basis, assess the feasibility of a mechanism to adjust the manufacturer's average specific CO2 emissions as f 2030. The detailed procedures for collecting and processing the data shall be adopted by means of implementing acts. [6] 


\section{Life-cycle emissions}

By 2023, the Commission shall evaluate the possibility of developing a common methodology for the assessment and reporting of the full life-cycle $\mathrm{CO} 2$ emissions of cars and vans. [6]

\section{Commission shall review}

The Commission shall review the effectiveness of the Regulation and report on this to the European Parliament and the Council.

This review shall cover the following [6]:

$>$ real world representativeness of the $\mathrm{CO} 2$ emission and energy consumption values,

$>$ deployment of ZLEV,

$>$ roll-out of recharging and refuelling infrastructure,

$>$ role of synthetic and advanced alternative fuels produced with renewable energy,

$>$ emission reductions observed for the existing fleet,

$>$ ZLEV incentive mechanism,

$>$ impacts for consumers,

$>$ aspects related to the just transition,

$>$ impacts for consumers, aspects related to the just transition,

$>2030$ targets and identification of a pathway for emission reductions beyond 2030 .

As part of the review, the Commission shall assess the feasibility of developing real-world emission test procedures, as well as the possibility to assign revenues from the fines to a specific fund or relevant programme with the objective to ensure a just transition towards a climate neutral economy.

Finally, the Commission shall review the Car Labelling Directive by end 2020, covering both CO2 and air pollutant emissions of cars and evaluating the options for introducing a fuel economy and $\mathrm{CO} 2$ emissions label for vans. [6]

In 2018, new car registrations in the EU remained roughly constant at 15.1 million. Possibly due to consumer uncertainty concerning Brexit, sales in the United Kingdom (UK) dropped by $7 \%$ compared to 2017. During the same time period, the market in Spain expanded by $7 \%$. By far the strongest growth in vehicle sales took place in the sport utility vehicle (SUV) segment. Approximately 5 million new cars in 2018 were SUVs, more than 8 times as many as in 2001. At the same time, small diesel, small gasoline, and medium-sized diesel vehicles - all with comparatively low CO2 emission values - lost more than 15 percentage points from 2015 to 2018. These relatively small vehicles were replaced by medium-sized gasoline vehicles and SUVs. The increase in the latter group was particularly problematic for fleet-average $\mathrm{CO} 2$ reductions, because SUVs had comparatively high $\mathrm{CO} 2$ emission values. [7]

In the aftermath of the Dieselgate scandal, sales of new diesel cars dropped significantly. In 2011-2012, about $55 \%$ of newly registered cars in the EU were powered by diesel fuel, an all-time high. Since then, the market share of diesel vehicles decreased slowly, to $49 \%$ in 2016, but then declined more quickly, to $36 \%$ in 2018 . In France, where the diesel market share used to be significantly higher than the EU average, the market share dropped from a high of $77 \%$ in 2008 to $39 \%$ by 2018 . This decline in diesel car sales began before Dieselgate and is likely related to the fact that the French government is equalizing taxes on diesel and gasoline fuel. In Germany, on the other hand, the diesel market share remained stable from 2011 to 2015 at about $48 \%$ but began dropping noticeably towards the end of 2016, declining to $30 \%$ in late-2018. This recent decrease in diesel car sales is likely due to a loss in trust from consumers who are increasingly concerned about the threat of diesel bans in urban areas. [7] 


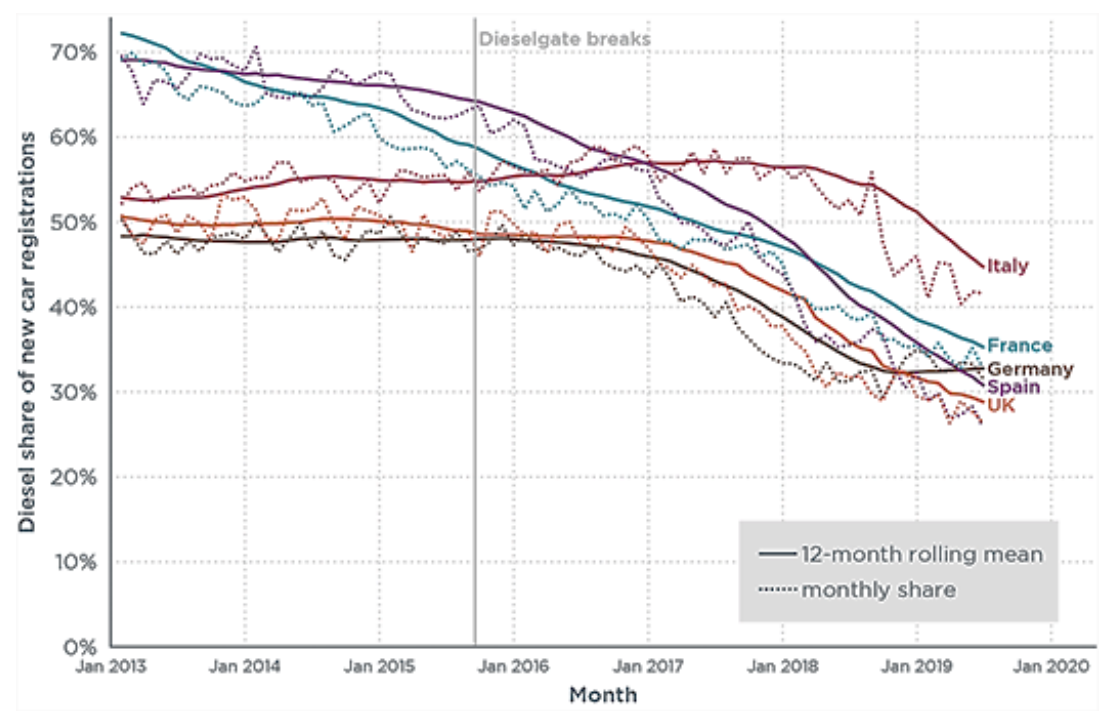

Figure 1. Historical development of the new car diesel market share in selected European member states Source: [7]

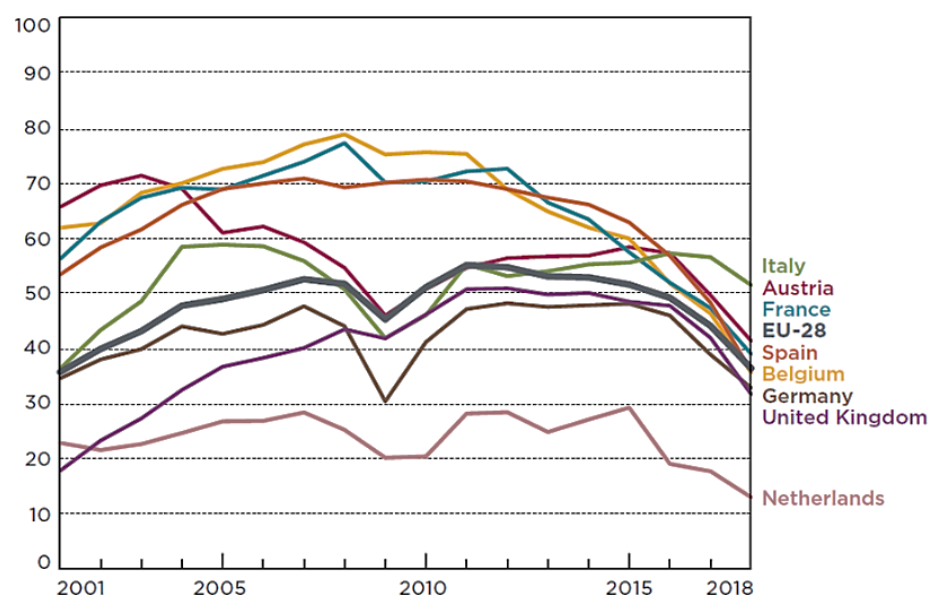

Figure 2. Market share of diesel vehicles (in \%)

Source: [7]

Within ten years, the diesel market share dropped from an EU-average of 52\% in 2008 to $36 \%$ in 2018. The decline of diesel has been particularly strong since 'Dieselgate' was uncovered in 2015. Today, only Volvo, Mercedes-Benz and BMW still sell more than 50\% of their new cars as diesel. On the other end of the spectrum, Toyota and Suzuki have successfully phased out new diesel vehicles. [7] 


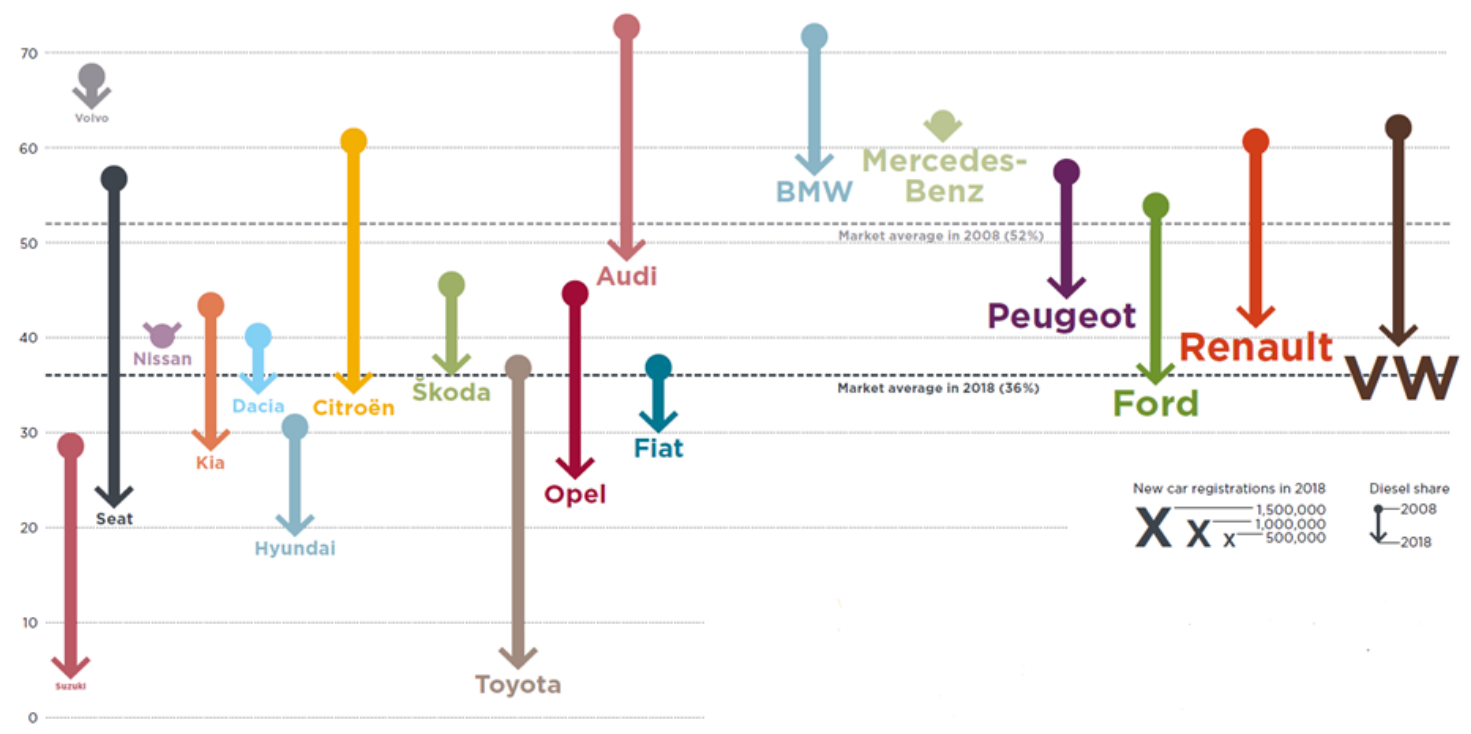

Figure 3. Diesel share of new car registrations by brand, 2008 to 2018.

\section{Source: [7]}

The vast majority of Europe's new cars are powered by gasoline or diesel motors. The market share of hybrid electric vehicles (HEV) in the EU was $3 \%$ of all new car sales in 2018. Sales of HEVs increased in particular in Finland, where the market share increased to $9 \%$ in 2018. Toyota continues to dominate the market for HEVs in Europe, with about $58 \%$ of all new Toyota vehicles in 2018 being hybrid electric. In 2018, plug-in hybrid (PHEV) and battery electric vehicles (BEV) each made up about $1 \%$ of new vehicle registrations in the EU. Top EU markets include Sweden, where $6 \%$ of new sales were PHEVs, and the Netherlands, where $5 \%$ of new sales were BEVs. Outside the EU, sales of electric vehicles are particularly high in Norway, where $18 \%$ of new cars sold in 2018 were PHEV, $31 \%$ were BEV, and an additional $11 \%$ were HEV. [7]

In terms of manufacturer brands, BMW was among the top sellers of PHEVs in 2018, with $5 \%$ of its new cars being equipped with this technology. Nissan led sales of BEVs models, with $6 \%$ of the brand's sales being battery electric. An analysis of the compliance options for selected manufacturers shows the respective 2021 $\mathrm{CO} 2$ targets can be met by deploying an increased share of electric vehicles. For a company such as BMW, it is estimated that by 2021 a market share of about $13 \%$ of PHEV and BEV will be required. [7]

The total market share of hybrid electric cars was $3 \%$ in 2018. Sales went up particularly in Finland, where it reached $9 \%$ in 2018. Hybrid electric cars were also relatively popular in Ireland, Spain and Sweden, with each having a $6 \%$ market share (Figure 4). Nearly $60 \%$ of all new vehicles manufactured by Toyota which are sold in the EU are hybrid electric. Sales of plug-in hybrid and battery electric vehicles each accounted for 1 $\%$ of all new cars in 2018. Plug-in hybrid cars were particularly successful in Sweden (6\%) and for the BMW brand $(5 \%)$. Battery electric vehicles reached the highest market share in the Netherlands $(5 \%)$ and for the Renault brand (3\%) (Figure 6.). [7] 


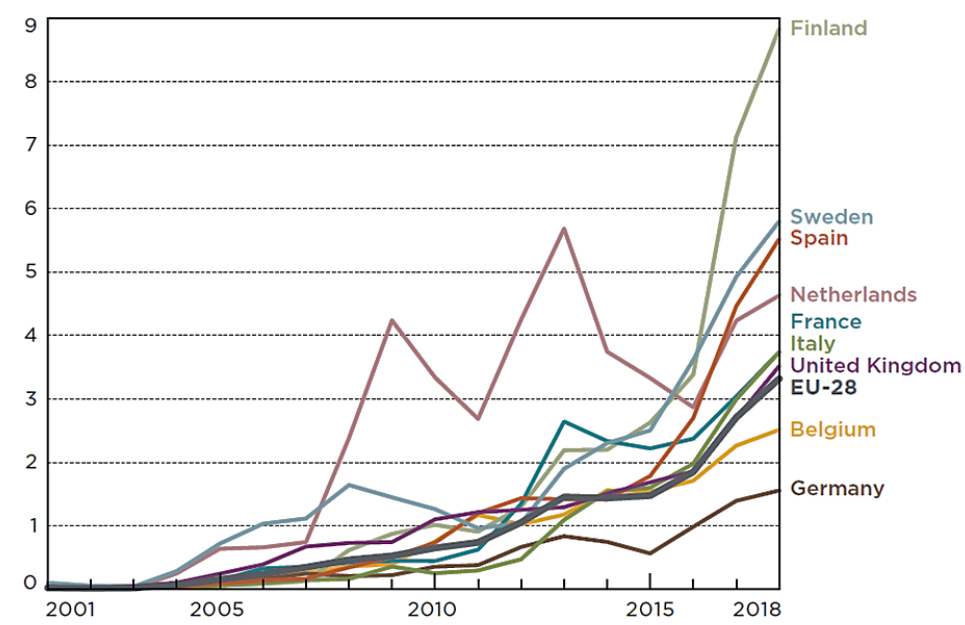

Figure 4. Market share of hybrid electric vehicles (in \%)

Source: [7]

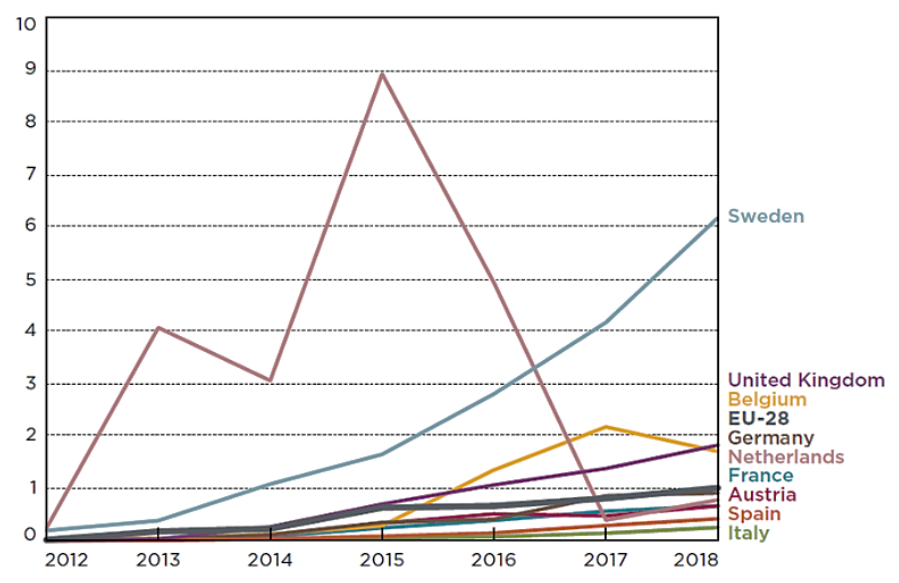

Figure 5. Market share of plug-in hybrid electric vehicles (in \%)

Source: [7]

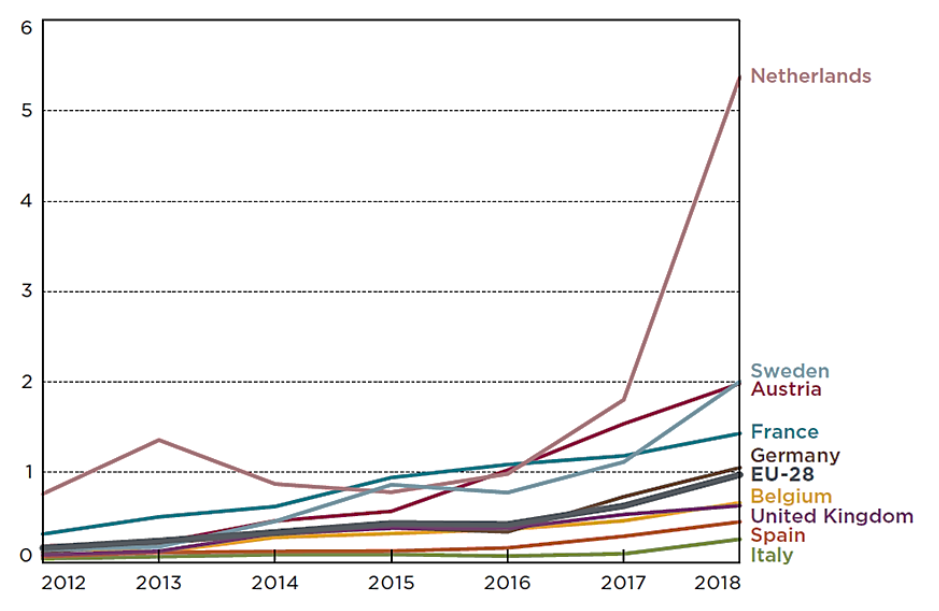

Figure 6. Market share of battery electric vehicles (in \%)

Source: [7] 


\section{Fuel consumption and $\mathrm{CO} 2$ emissions}

The official level of average carbon dioxide (CO2) emissions from new passenger cars in the EU, as measured in the laboratory via the New European Driving Cycle (NEDC) type-approval test procedure, increased to 120 grams per kilometer $(\mathrm{g} / \mathrm{km})$ in 2018, which is $2 \mathrm{~g} / \mathrm{km}$ higher than in the previous year (Tietge, 2019). As CO2 emissions and fuel consumption are directly linked, this implies a fleetwide average fuel efficiency of 5 liters $/ 100 \mathrm{~km}$. Before $\mathrm{CO} 2$ standards were introduced, emissions of new passenger cars in the EU, on average, declined by $1.2 \%$ per year from 2000 to 2007 . When the first mandatory CO2 standards were agreed upon in 2008, manufacturers significantly outperformed the annual reduction rates required to meet the 2015 target of $130 \mathrm{~g} / \mathrm{km}$; instead of the required $2.5 \%$ annual reduction, average $\mathrm{CO} 2$ emissions declined by $3.5 \%$ per year. After 2015 targets were met, and in the absence of targets before 2020, average CO2 emissions increased by $0.3 \%$ per year. As of 2018 , fleet-average $\mathrm{CO} 2$ emissions will have to decline by $7.6 \%$ per year to comply with the 2021 target. Manufacturers will likely rely to a larger degree on flexible compliance mechanisms such as super-credits and eco-innovations to comply with 2020/21 targets. [8]

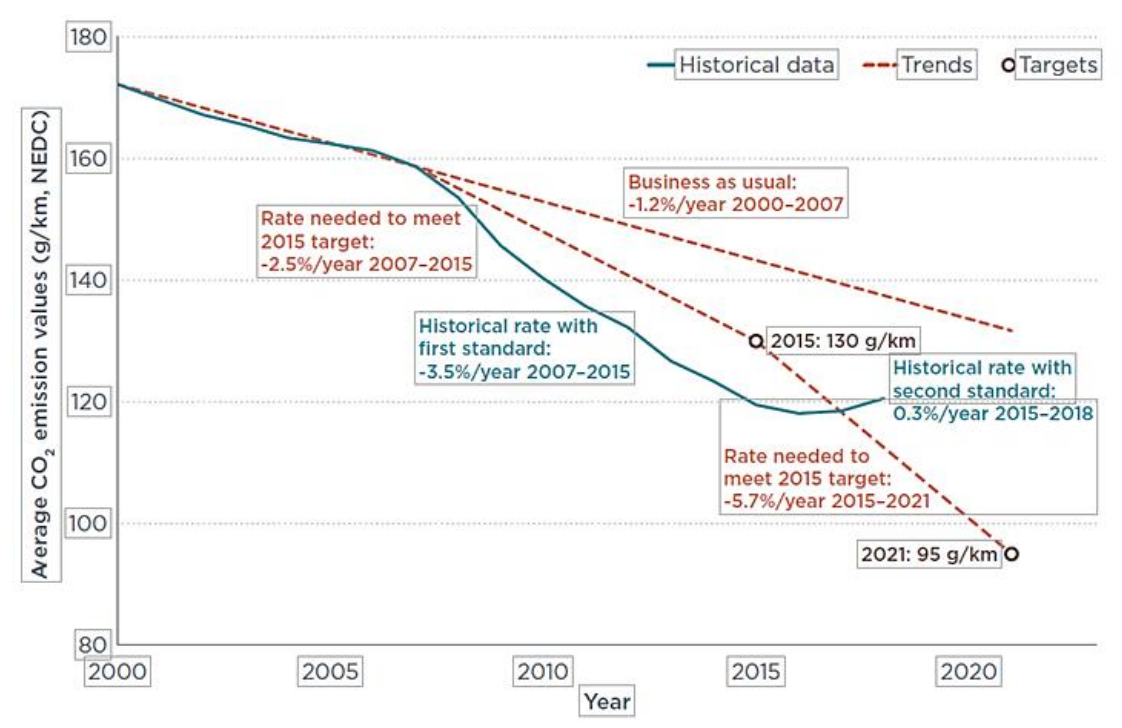

Figure 7. Emissions from new passenger cars in the EU

Source: [8]

\section{Planned national sales or registration bans}

National sales or registration bans have been officially announced in a number of Member States in the last few of years. In 2017, Norway (which as an EEA member takes part in the Single Market) adopted the goal that all new cars sold by 2025 should be zero-emission vehicles (electric or hydrogen), equating to a sales ban on all ICE vehicles by that date18. The Netherlands have also set a similar target for 203019 , as well as Ireland20, while Scotland aims to achieve this by 203221, and Britain 22 and France23 by 2040. It should be noted that these targets are mostly only laid out in strategic documents and do not have legal force. The French target was however formally adopted on 19 November 2019, setting into law the objective of ending sales of passenger cars and light commercial vehicles using fossil fuels by 2040. No plans have currently been announced to ban ICEs for heavy-duty vehicles. [4]

\section{Conclusion}

Vehicle market, both passenger and commercial, is rapidly and indisputably changing. With the new innovations and ecological requirements for better and cleaner environment, there is no place for stagnation on one of the most competitive market in the world. 
Although increase in sales of "clean" vehicles as hybrids, plug in hybrids and battery electric vehicles are closely tied to the government incentives, local regulations and fuel prices, constant rise of sales numbers is observed.

Evan in highly challenging 2020, electric and plug in hybrid vehicles saw increase in sales. Not only in terms of their market share, but also in absolute terms. In Germany, EV sales from January to June increased from 47,584 in 2019 to 93,848 in 2020, supported by particularly strong PHEV growth.

With the automotive world changing, CAFE regulative are perfectly reflecting current trends. With the next year determined as the benchmark, $\mathrm{CO} 2$ targets are defined as a percentage reduction from the 2021. $15 \%$ reduction for 2025 on and $37.5 \%$ reduction for 2030 .

Ecology is becoming one of the major factors of automotive industry with lot of manufactures supporting the trend and trying to become carbon neutral.

\section{References}

[1] European Environment Agency. Greenhouse gas emissions from transport in Europe. Available at: https://www.eea.europa.eu/data-and-maps/indicators/transport-emissions-of-greenhousegases/transport-emissions-of-greenhouse-gases-12 [Accessed: October 15, 2020]

[2] European Environment Agency. Air quality in Europe - 2019 report. EEA. Denmark. 2019.

[3] European Commission. CAFE Reference Documents. Available at: https://ec.europa.eu/environment/archives/cafe/general/keydocs.htm [Accessed: October 10, 2020]

[4] European Commission. Reducing CO2 emissions from passenger cars - before 2020. Available at: https://ec.europa.eu/clima/policies/transport/vehicles/cars_en [Accessed: October 10, 2020]

[5] International Council on Clean Transportation. Overview and evaluation of eco-innovations in European passenger car CO2 standards. Icct. Washington. 2018.

[6] European Commission. $\mathrm{CO}_{2}$ emission performance standards for cars and vans (2020 onwards). Available at: https://ec.europa.eu/clima/policies/transport/vehicles/regulation_en [Accessed: October 05, 2020]

[7] International Council on Clean Transportation. European vehicle market statistics: Pocketbook 2019/20. Icct. Berlin. 2019.

[8] International Council on Clean Transportation. $\mathrm{CO} 2$ emissions from new passenger cars in Europe: Car manufacturers' performance in 2019. Icct. Berlin. 2020. 